\title{
Plasma Polyethylene Glycol (PEG) Levels Reach Steady State Following Repeated Treatment with N8-GP (Turoctocog Alfa Pegol; Esperoct ${ }^{\circledR}$ )
}

\author{
Inga Bjørnsdottir ${ }^{1}\left[\mathbb{C}^{\circ} \cdot\right.$ Birgitte Støvring $^{1} \cdot$ Tue Søeborg $^{1} \cdot$ Helene Jacobsen $^{1} \cdot$ Ola Sternebring $^{1}$
}

Published online: 9 March 2020

(c) The Author(s) 2020

\begin{abstract} periods of up to 5 years. pected increase in PEG was observed.

\section{Key Points}

Plasma polyethylene glycol (PEG) concentrations were analysed in rats and humans treated repeatedly with the PEGylated factor VIII product N8-GP (turoctocog alfa pegol; Esperoct ${ }^{\circledR}$ ) for periods of up to 1 year (rats) and 5 years (humans).

Measured PEG concentrations in plasma were shown to align with values predicted using a semi-mechanistic plasma-tissue pharmacokinetic model based on a singledose pharmacokinetics and distribution study conducted in rats.
\end{abstract}

Background Extended half-life (EHL) factor VIII (FVIII)-replacement therapies enable patients with haemophilia A to maintain higher activity levels with fewer injections. N8-GP (turoctocog alfa pegol; Esperoct ${ }^{\circledR}$ ) is an EHL product derived from conjugation of polyethylene glycol (PEG) to a recombinant FVIII protein. Upon activation, PEG is released from the active protein and excreted in urine and faeces. While PEG levels are expected to reach steady state with repeated dosing, there has been some discussion regarding whether abnormal accumulation of PEG in plasma and tissues may occur.

Objective Our objective was to examine plasma PEG concentrations in rats and humans repeatedly treated with N8-GP for

Methods PEG levels were measured using liquid chromatography-tandem mass spectrometry in plasma samples from rats treated with N8-GP as part of a 52-week toxicity study. Human plasma samples from children, adolescents and adults treated with N8-GP as part of the pathfinder programme were also examined (NCT01731600; NCT01480180). These data were compared with steady-state PEG levels predicted by pharmacokinetic modelling of single-dose rat data.

Results PEG levels reached steady state in plasma in both rats and humans after repeated dosing. The timing and degree of PEG increase to steady state were in line with or below model predictions, confirming the utility of the pharmacokinetic model and indicating that rat data can be used to estimate human plasma PEG levels.

Conclusion Steady-state PEG levels were reached in plasma from rats and humans repeatedly treated with N8-GP. No unex-

PEG levels reached steady state in plasma from rats and humans treated with N8-GP, and there was no unexpected increase above steady-state levels.

Inga Bjørnsdottir

INBJ@ novonordisk.com

1 Novo Nordisk A/S, Novo Nordisk Park, 2760 Måløv, Denmark

\section{Introduction}

Haemophilia A is a serious and potentially life-threatening bleeding disorder caused by a genetic deficiency in clotting factor VIII (FVIII). The classical way of treating haemophilia A has been replacement therapy with the missing clotting factor, either as on-demand treatment when bleeding occurs or as prophylactic treatment to prevent bleeding episodes. Because unmodified FVIII products have a relatively short half-life of 8-12 h [1], several FVIII products with prolonged systemic circulation have been developed to maintain higher FVIII activity levels with fewer injections.

One of the most widely used techniques to extend the circulation half-life of a protein/peptide is via conjugation with polyethylene glycol (PEG). PEGylation results in half-life prolongation because of (1) decreased renal excretion resulting from an increase in the hydrodynamic volume of the molecule and (2) slower enzymatic degradation of the active moiety because the protein backbone is shielded [2]. The principle of PEGylation has been applied 
to N8-GP [turoctocog alfa pegol; Esperoct ${ }^{\circledR}$ (Novo Nordisk A/S, Denmark)], an extended half-life FVIII molecule that has been approved for the treatment of haemophilia A in the EU, USA, Canada, Switzerland, and Japan. N8-GP is derived from the site-directed conjugation of a singlebranched, 40-kDa PEG molecule to a unique $O$-linked glycan in the B domain of the recombinant FVIII (rFVIII) protein N8 [turoctocog alfa; NovoEight ${ }^{\circledR}$ (Novo Nordisk $\mathrm{A} / \mathrm{S})$ ] [3]. It has a safety profile similar to that of unmodified FVIII products and improved pharmacokinetics [4-6].

In general, PEGylated protein/peptide conjugates can be considered to comprise two distinct and structurally different moieties: (1) the active moiety (the protein/peptide) and (2) the PEG moiety. When the PEGylated protein is taken up by tissues, the active component is degraded by proteases, and fragments are excreted (Fig. 1). The enzymatically and chemically stable PEG moiety is then released intact back into the circulation and subsequently excreted, predominantly in urine [7]. The respective protein/peptide and the PEG moiety are therefore eliminated from tissues and plasma at different rates. This difference in biological fate and thereby also in kinetics has resulted in concerns regarding long-term exposure to PEGylated drugs and the hypothetical potential for the accumulation of PEG in certain tissues (e.g. the choroid plexus, kidney and liver), possibly adversely impacting their function $[8$, 9]. However, these concerns are only valid if the PEG moiety is not eliminated from tissues or plasma or if the dose and exposure level is adversely high [10].

Elimination of PEG from tissues and plasma has been demonstrated in various animal species with a number of PEGylated proteins [11-13]. For N8-GP, the tissue distribution of PEG was previously investigated in rats receiving a single bolus dose of either N8-GP containing a $\left[{ }^{3} \mathrm{H}\right]$-labelled PEG moiety or $40-\mathrm{kDa}\left[{ }^{3} \mathrm{H}\right] \mathrm{PEG}$ alone [14]. N8-GP and PEG were shown to be widely distributed without selective distribution to any organ or tissue. As expected, radiolabelled PEG molecules were eliminated from all organs and excreted intact in both urine and faeces. The majority of radioactivity was excreted within 1-2 weeks after dosing.

PEG levels in plasma and tissues are governed by the PEG dose, dose frequency and duration of treatment. Since the elimination rate of PEG is slower than that of FVIII, it is to be expected, based on basic pharmacokinetic principles that repeated dosing leads to an initial increase in PEG levels until a plateau concentration (steady-state level) is reached. Steady-state levels are then maintained when input (dose amount and frequency) and output (elimination) rates are in equilibrium (Fig. 2). Again, according to pharmacokinetic theory, the general rule is that the time to reach steady state is determined by the elimination halflife. Though steady state is often said to be achieved after

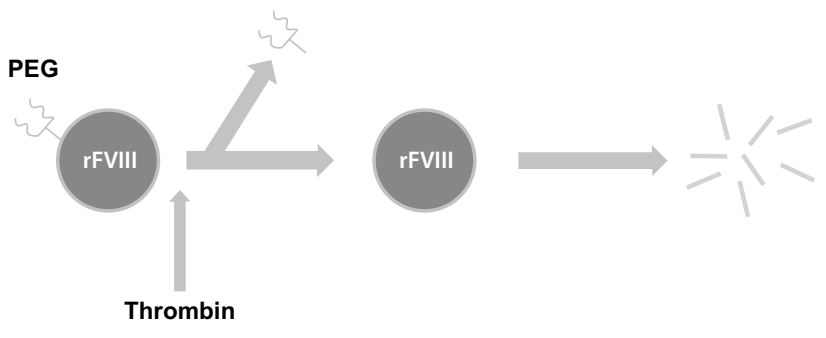

Fig. 1 Turoctocog alfa pegol (N8-GP) comprises two distinct moieties with differing pharmacokinetic characteristics. The 40-kDa PEG moiety is attached to an $O$-linked glycan in the 21-amino acid truncated $\mathrm{B}$ domain of rFVIII (turoctocog alfa). Upon activation, the $\mathrm{B}$ domain harbouring the PEG moiety is cleaved from the rFVIII molecule, leaving two separate molecules with different half-lives (i.e. the free PEG and the activated rFVIII molecule) [3]. PEG polyethylene glycol, $r F$ VIII recombinant factor VIII

approximately five times the half-life of the molecule [15], in clinical practice, steady state can be considered to have been reached after 3.3 times the half-life where $\sim 90 \%$ of steady-state levels have been achieved [16].

The consequences of different steady-state PEG levels can be assessed in repeat-dose toxicology studies. For N8-GP, a 52-week repeat-dose toxicology study in Rowett nude rats was conducted with intravenous administration at a dose range of 50-1200 IU/kg every 4 th day (Q4D) [17]. No treatment-related adverse reactions or treatmentrelated changes in any organ were reported in this study, even at doses far beyond the clinical dose (maximum dose cohort: $1200 \mathrm{IU} / \mathrm{kg}$ Q4D). PEG was also not detected in brain or choroid plexus tissue over the duration of the 52 -week study in rats treated with the maximum dose.

Even though no adverse findings were reported in the rat toxicology study, analysis of PEG plasma exposure is valuable to demonstrate that expected steady-state levels are reached. Plasma PEG levels can also serve as a surrogate marker to show the extent of tissue exposure in animal and human studies. However, analysis of PEG plasma concentrations was not originally planned in the N8-GP rat toxicology study as assays available at the time of conduct did not have the level of sensitivity required. Instead, steadystate plasma and tissue concentrations were predicted using a semi-mechanistic plasma-tissue pharmacokinetic model based on a single-dose pharmacokinetic and distribution study conducted in rats [14].

Recently, a contract research organisation was identified that could analyse low plasma PEG concentrations using a sensitive liquid chromatography-tandem mass spectrometry (LC-MS/MS) method. Therefore, leftover plasma samples from the chronic rat toxicity study could be used to retrospectively analyse plasma PEG levels. In addition, human plasma samples from the pathfinder clinical trial programme, which aimed to examine the pharmacokinetics, 


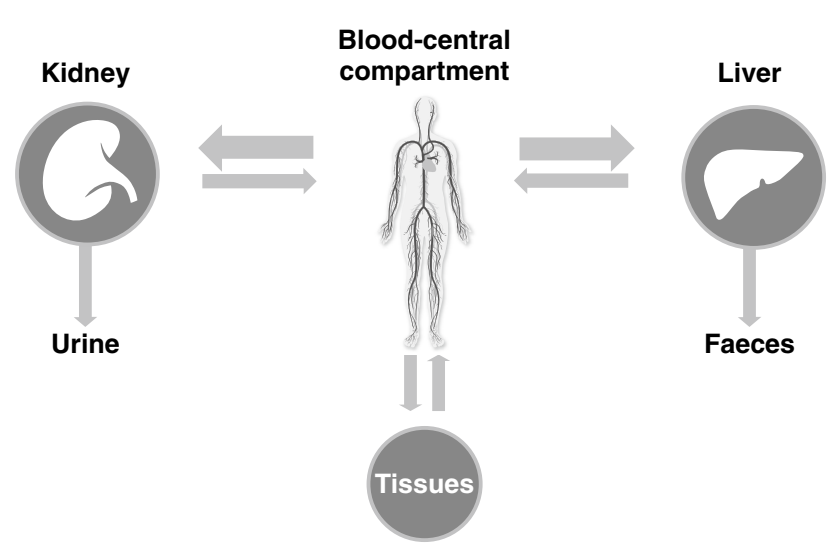

Fig. 2 Steady-state PEG levels are expected in patients receiving chronic treatment with PEGylated molecules. Steady state is achieved when there is equilibrium between the rate of input into plasma (dose and dosing frequency) and the rate of output (elimination from the tissue) $[7,8]$. PEG is excreted predominantly via urine but also in faeces in small amounts [14]. PEG polyethylene glycol

safety and efficacy of N8-GP in adult/adolescent patients aged $\geq 12$ years (pathfinder 2 ; NCT01480180) and children aged $<12$ years (pathfinder5; NCT01731600), were also available for analysis. Although PEG plasma exposure was not initially part of the clinical protocol, it could also be measured retrospectively, with consent, in duplicate samples collected for analysis of antidrug antibodies.

Here, we describe measured PEG plasma concentrations in rats and humans following repeated dosing with N8-GP. Measured PEG levels in rats and humans were compared with steady-state levels predicted using a semimechanistic plasma-tissue pharmacokinetic model developed based on single-dose rat distribution data.

\section{Material and Methods}

\subsection{Laboratory Animals}

Unused plasma samples from an antidrug antibody analysis performed during a chronic 52-week toxicity study in Rowett nude rats were selected [17]. A total of 159 plasma samples were analysed from individual male rats receiving $0,50,150,500$, or $1200 \mathrm{IU} / \mathrm{kg}$ of N8-GP Q4D. PEG levels were also analysed 2 weeks after treatment cessation in the highest dose group. To calculate mean PEG exposure, samples that were below the lower limit of quantification (LLoQ) were set to half of the LLoQ defined in Sect. 2.3.

\subsection{Patients and Sample Collection}

A total of 184 human plasma samples from 62 paediatric patients and 121 adolescent/adult patients treated with N8-GP were analysed by LC-MS/MS (two samples were obtained from one paediatric patient). Paediatric samples were taken from patients after $\sim 3-4.5$ years of $60 \mathrm{IU} / \mathrm{kg}$ twice-weekly dosing with N8-GP as part of the pathfinder5 trial [5]. Adult/adolescent samples were taken after $\sim 2-5$ years of $50 \mathrm{IU} / \mathrm{kg}$ Q4D dosing with N8-GP as part of pathfinder2 $[4,18]$. To calculate mean PEG exposure, samples that were below the LLoQ were set to half of the LLoQ defined in Sect. 2.3.

\subsection{Liquid Chromatography-Tandem Mass Spectrometry Method for PEG Analysis}

Quantification of total PEG (sum of free and conjugated) was performed in rat and human plasma samples by LC-MS/MS. Briefly, rat and human plasma samples were prepared for analysis by adding an internal standard (D-PEG-60k) and pronase protease. After mixing on a thermomixer, $\mathrm{MeOH}$ was added prior to LC-MS/MS analysis. Samples were measured with an API6500 Q-trap mass spectrometer (Ab Sciex, Canada), and data were analysed using Analyst ${ }^{\circledR}$ 1.6.2 software (Ab Sciex, Canada). The LLoQ was $13.7 \mathrm{ng} / \mathrm{mL}$ in rat plasma and $10 \mathrm{ng} / \mathrm{mL}$ in human plasma. Data acquisition and analysis were performed by pharm-analyt Labor GmbH, Baden, Austria.

\subsection{Model Prediction}

The pharmacokinetic model that was used to predict PEG exposure in the chronic rat toxicity study and human trials was a semi-mechanistic, multi-compartment, plasma-tissue model created in Phoenix ${ }^{\circledR}$ WinNonlin ${ }^{\circledR}$ version 6.4 (Certara USA, Inc., Princeton, NJ, USA) using the non-linear mixedeffect module. The model was based on a single-dose rat N8-GP distribution study using a radiolabelled PEG moiety [14] that simultaneously described the plasma and tissue radioactivity data with plasma concentrations driving tissue levels. Standard allometric scaling of the relevant model parameters was performed in order to predict plasma and tissue PEG levels in humans. 


\section{Results}

\subsection{Plasma PEG Levels Did Not Increase Over Time in Samples Obtained from Rats Receiving N8-GP as Part of a 52-Week Toxicity Study}

While all plasma samples from the 0 and $50 \mathrm{IU} / \mathrm{kg}$ Q4D dose groups were below the LLoQ $(<13.7 \mathrm{ng} / \mathrm{mL})$, plasma PEG concentrations increased in a dose-dependent manner over the 150-1200 IU/kg dose range (Fig. 3). For the dose levels with detectable PEG levels (150-1200 IU/kg), mean plasma PEG concentrations remained stable over the study period and did not increase between 26 and 52 weeks (Fig. 3). Mean plasma PEG levels decreased from 85.1 to $33.0 \mathrm{ng} / \mathrm{mL}$ after 2 weeks' recovery in the highest dose group. Measured plasma PEG levels were in line with the model-predicted steady-state levels. In addition, the model also represented the observed decline in the mean plasma PEG concentration seen after treatment cessation. Steady-state plasma PEG levels were predicted to have been reached within 1.5 months of the 52-week (12-month) dosing period (Fig. 3).

\subsection{Plasma PEG Levels Reached Steady State in Children, Adolescents and Adults Receiving Long-Term Treatment with N8-GP}

Measured mean PEG plasma concentrations for children, adolescents and adults receiving treatment with N8-GP for periods of up to 5 years are reported in Table 1. Of a total of 184 human samples analysed, 51 adult and adolescent patient samples were below the LLoQ $(10 \mathrm{ng} / \mathrm{mL})$. Detectable PEG concentrations ranged from 10.0 to $35.9 \mathrm{ng} / \mathrm{mL}$ in plasma from paediatric patients and from 10.1 to $34.2 \mathrm{ng} / \mathrm{mL}$ in adults and adolescents. Interpatient variation in plasma PEG levels was relatively low.

Figure 4 shows the measured plasma PEG concentrations from individual children, adolescents and adults along with the model-predicted steady-state PEG level. Although the dose in children was slightly higher than in adults (60 IU/kg twice weekly vs. $50 \mathrm{IU} / \mathrm{kg}$ Q4D), modelpredicted steady-state PEG concentrations were similar in children and adults. This is likely due to the faster clearance rate in children. Steady-state plasma PEG concentrations in patients were predicted to be reached within 6 months. The
Fig. 3 Predicted and measured PEG concentrations in plasma from rats after 26 and 52 weeks' exposure to N8-GP and 2 weeks after treatment cessation. Predicted (solid lines) and measured (squares \pm standard deviation) PEG concentrations are shown. To calculate mean PEG exposure, values $<$ LLoQ were set to $6.85 \mathrm{ng} / \mathrm{mL}$, which was half of the LLoQ. In the high-dose group (1200 IU/kg), mean PEG values were $92.8 \mathrm{ng} / \mathrm{mL}$ ( 26 weeks), $85.1 \mathrm{ng} / \mathrm{mL}$ (52 weeks) and $33.0 \mathrm{ng} / \mathrm{mL}$ (54 weeks). $L L o Q$ lower limit of quantification, $N 8-G P$ turoctocog alfa pegol, $P E G$ polyethylene glycol, $Q 4 D$ every 4th day

Table 1 Measured PEG levels in children, adolescent and adults after $3-5$ years of exposure to N8-GP

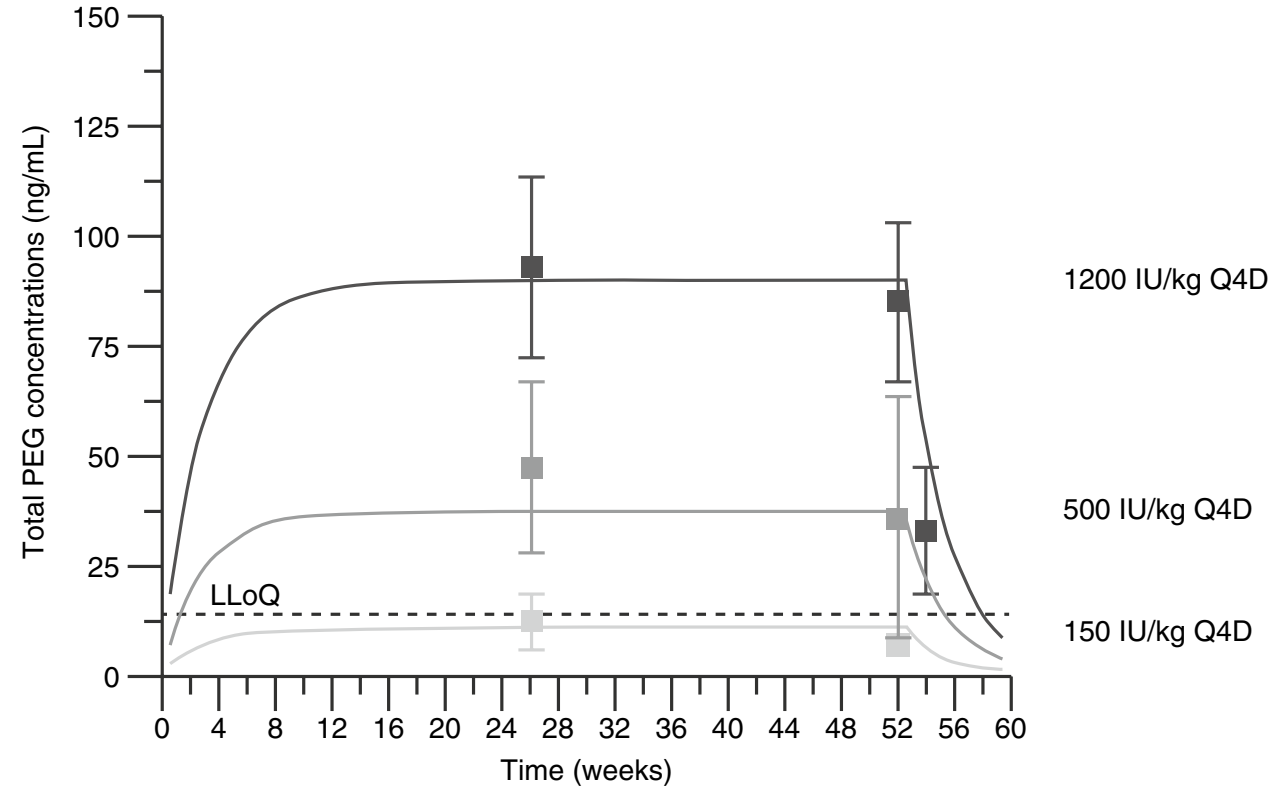

\begin{tabular}{|c|c|c|c|c|}
\hline Treatment group & Dose (IU/kg) & Dose interval & $n$ & $\begin{array}{l}\text { Mean plasma } \\
\text { PEG levels } \\
(\mathrm{ng} / \mathrm{mL} \pm \mathrm{SD})\end{array}$ \\
\hline Children & 60 & Twice weekly & 63 & $18.5 \pm 6.9$ \\
\hline Adults and adolescents ${ }^{\mathrm{a}}$ & 50 & Q4D & 121 & $10.7 \pm 5.5$ \\
\hline
\end{tabular}

$L L o Q$ lower limit of quantification, N8-GP turoctocog alfa pegol, $P E G$ polyethylene glycol, $Q 4 D$ every 4 th day, $S D$ standard deviation

${ }^{a}$ Of a total of 121 samples analysed, 51 samples were below the LLoQ. To calculate mean PEG levels, these samples were set to half the LLoQ $(5 \mathrm{ng} / \mathrm{mL})$ 
actual measured plasma PEG concentrations in humans were slightly lower than predicted.

\section{Discussion}

Development of the PEGylated N8-GP molecule has enabled extension of the mean terminal half-life to $19 \mathrm{~h}$, which was observed to be 1.6-fold higher than the patients' previous standard FVIII products [6]. Once separated, the two distinct parts of N8-GP, that is the rFVIII and the attached PEG molecule, exhibited different pharmacokinetic characteristics and make use of discrete elimination pathways. As free PEG has a longer terminal half-life in plasma than rFVIII, concerns have been raised regarding potential abnormal or even indefinite PEG accumulation with repeated administration of PEGylated coagulation factors in plasma and tissues.

Data presented here show that plasma PEG levels reach steady state in both rats and humans over an extended dosing period and do not increase further. Steady-state plasma PEG levels were predicted to have been reached within the first 1.5 months in rats and within 6 months in humans. In rats, plasma PEG levels decreased markedly within 2 weeks following N8-GP treatment cessation, suggesting that PEG is removed relatively rapidly from plasma once treatment ceases. The rate of decline was in line with the plasma halflife of PEG observed in the single-dose rat study [10]. As expected, human plasma PEG levels were several fold lower (five- to eightfold) than those reported at the no-observedadverse-effect-level in the rat toxicity study [17]. PEG exposure in children was slightly higher than in adults and adolescents, which is likely due to the higher N8-GP (and therefore PEG) dose combined with a shorter dose interval (60 IU/kg twice weekly in the paediatric trial vs. $50 \mathrm{IU} / \mathrm{kg}$ Q4D in the adult/adolescent trial).

The semi-mechanistic plasma-tissue pharmacokinetic model based on single-dose distribution data from rats was successful in predicting multiple-dose plasma exposures in rats and humans. The alignment of the measured plasma PEG levels with the model prediction indicates that PEG kinetics are predictable, they adhere to basic pharmacokinetic principles, and are scalable between rats and humans. As only single samples were available from patients receiving N8-GP, full PEG concentration profiles for individual patients could not be analysed. Based on this predictability for rat and human plasma (concentration levels and time to steady state), it seems plausible that rat tissue kinetics would also be predictive for human tissue. This is important as it is not feasible to measure PEG in human tissues.

Data described here for N8-GP also align with those from a recent study examining PEG exposure in patients treated long term with N9-GP, a 40-kDa PEGylated recombinant Factor IX product [nonacog beta pegol; Refixia ${ }^{\circledR}$ (Novo Nordisk A/S)] [19]. This study, which included more samples from each patient, showed that steady-state plasma PEG levels were reached approximately 6 months after initiation of treatment with N9-GP. Plasma PEG levels remained at steady-state concentrations, with trough concentrations of around $5.5 \mu \mathrm{g} / \mathrm{mL}$ in paediatric, adolescent and adult patients over the observed treatment period lasting up to 6.5 years and did not accumulate further. No safety issues were reported that were attributable to PEG, and the safety profile was similar to those of other Factor IX products [20, 21].

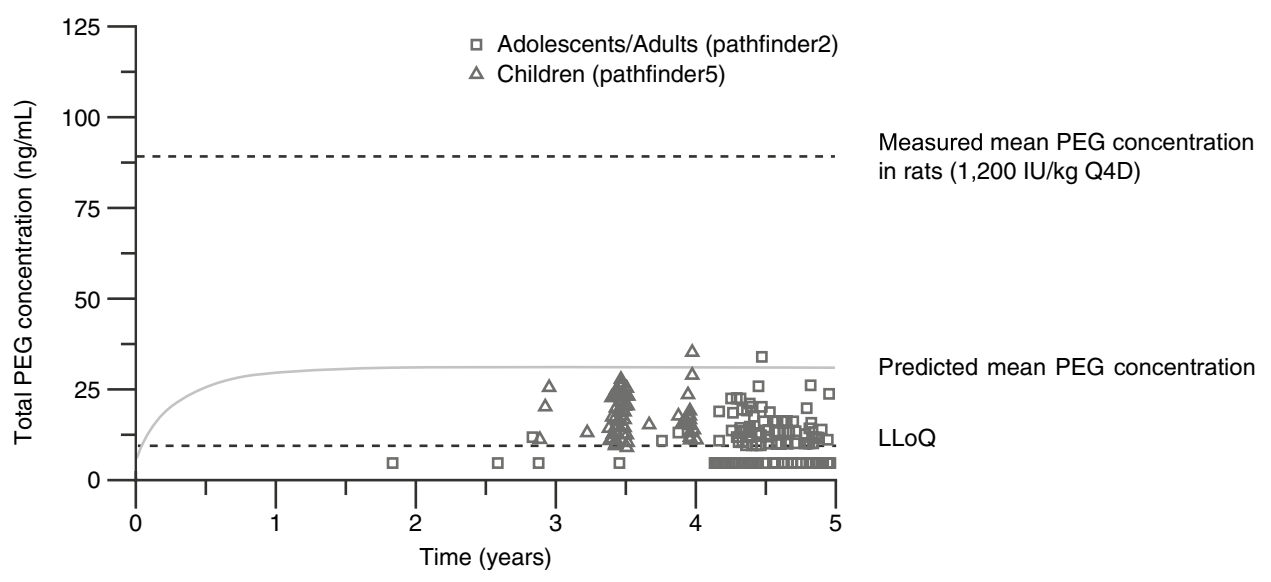

Fig. 4 Predicted and measured PEG concentrations in children, adolescents and adults measured after 2-5 years of exposure to N8-GP. Children (pathfinder5) were treated with $60 \mathrm{IU} / \mathrm{kg}$ N8-GP twice weekly (open triangles) [5]. Adolescents and adults (pathfinder2) were treated with $50 \mathrm{IU} / \mathrm{kg}$ N8-GP Q4D (open squares) $[4,6]$. Mean PEG exposure during the 52-week rat toxicity study [17] is indicated by the upper dotted line, and the LLoQ is shown by the lower dotted line. Predicted mean PEG exposure in children, adolescents and adults (grey solid line) is shown as a reference. The mean measured plasma PEG concentration for children, adolescents and adults was $13.3 \mathrm{ng} / \mathrm{mL}$. $L L o Q$ lower limit of quantification, $N 8-G P$ turoctocog alfa pegol, $P E G$ polyethylene glycol, $Q 4 D$ every 4 th day 
In addition to N8-GP, two other PEGylated FVIII products indicated for the treatment of haemophilia A are currently on the market: BAX 855 [rurioctocog alfa pegol; Adynovate ${ }^{\circledR} /$ Adynovi ${ }^{\circledR} ; 20-\mathrm{kDa}$ PEG (Takeda, Tokyo, Japan)] and BAY 949027 [damoctocog alfa pegol; Jivi ${ }^{\circledR}$; 60-kDa PEG (Bayer, Leverkusen, Germany)] (Table 2). PEG exposure from a PEGylated rFVIII is expected to be generally low because of the high potency (IU per $\mathrm{mg}$ ) and low plasma concentration of FVIII ( $1 \mathrm{IU} / \mathrm{mL}$ equals 100-200 ng/mL in healthy humans [22]). However, limited PEG exposure data are currently available in the literature. The size of the PEG moiety differs between molecules (20-60 kDa), but the weekly PEG load is comparable. Both predicted and measured plasma PEG concentrations were recently described for BAY 949027 [23, 24]. Simulations using pharmacokinetic data from a rat tissue distribution study predicted a steady-state plasma PEG concentration of $100 \mathrm{ng} / \mathrm{mL}$ in humans. Of 179 patients treated with BAY 949027 for 0.8-5.4 years, five had detectable plasma PEG concentrations above the LLoQ (100 ng/mL), and the maximum detectable PEG measurement was $119 \mathrm{ng} / \mathrm{mL}$. The applied simulation approach was therefore said to reasonably predict plasma PEG levels in patients treated with BAY 94 9027. By comparison, the mean measured PEG level for all N8-GP-treated patients was $13.3 \mathrm{ng} / \mathrm{mL}$, and the highest measured value was $35.9 \mathrm{ng} / \mathrm{mL}$ (Table 2). Clearance is known to decrease with larger PEG molecules, which could explain the differences in steady-state concentrations between the molecules [25]. No human PEG plasma exposure data have been reported for BAX 855, which has a shorter PEG moiety (20 kDa) but approximately two- to fourfold higher weekly PEG load than N8-GP (clinical PEG dose per week of 7.6-9.5 $\mu \mathrm{g} / \mathrm{kg}$ for BAX 855).

While some concerns have been raised regarding the potential for PEG levels to continue to rise during repeated use of PEGylated products [26], none of the studies examining currently approved PEGylated coagulation factors have reported unexpected PEG accumulation or specific PEGrelated safety issues. A recent publication reported significant adverse microscopic alterations to tissue architecture in monkeys administered a 12-kDa protein PEGylated with a 40-kDa PEG moiety. The adverse cell morphology was only seen in the highest dose group with a very high PEG dose of $160 \mathrm{mg} / \mathrm{kg} /$ week administered for 3 months, and not in groups receiving $120 \mathrm{mg} / \mathrm{kg} /$ week PEG or lower [10]. The human equivalent dose of PEG [27] corresponding to the highest dosing group is $51 \mathrm{mg} / \mathrm{kg} /$ week, which is around 13,000 times higher than the maximum clinical PEG dose achieved with regular N8-GP use ( $4 \mu \mathrm{g} / \mathrm{kg} /$ week). Thus, the PEG dose that contributed to the observed adverse effects on tissue architecture in monkeys is much higher than that achieved with a clinically relevant dose of N8-GP.

Novo Nordisk has assessed all available safety data from 270 patients, including 68 children and 202 adolescents and adults, with up to 5 years of regular prophylactic N8-GP exposure. While the ability for PEG to reach steady state in plasma does not exclude the possibility of longer-term (lifetime) safety concerns, no unexpected safety concerns have been identified so far, and there have been no indications of neurological, renal or hepatic adverse reactions. The safety profile observed for N8-GP was similar to that reported for other (non-PEGylated) FVIII products, including the nature and frequency of the adverse events reported, and no adverse events could be attributed to the presence of PEG [28].

\section{Conclusion}

Steady-state plasma PEG levels were shown to have been reached in rats and humans receiving regular doses of N8-GP for periods of up to 5 years. Once steady state was reached, no further increase in PEG levels was observed. Plasma steady-state concentrations of PEG in humans were

Table 2 PEG dose and exposure from approved PEGylated FVIII molecules indicated for prophylactic treatment of haemophilia A

\begin{tabular}{|c|c|c|c|c|c|}
\hline Product & EU approval & PEG size, $\mathrm{kDa}$ & Typical dose described in label & $\begin{array}{l}\text { Clinical PEG } \\
\text { dose per week, } \\
\mu \mathrm{g} / \mathrm{kg}\end{array}$ & $\begin{array}{l}\text { Clinical PEG steady-state } \\
\text { plasma concentration, } \\
\text { ng/mL }\end{array}$ \\
\hline BAY 949027 & 2018 & 60 & $\begin{array}{l}60 \mathrm{IU} / \mathrm{kg} \text { every } 5 \text { th day or twice weekly [11] } \\
(84-120 \mathrm{IU} / \mathrm{kg} / \text { week })\end{array}$ & $2.8-4.0$ & $<100^{\mathrm{a}}$ \\
\hline N8-GP & 2019 & 40 & $\begin{array}{l}\text { 50-60 IU/kg Q4D or twice weekly [29] } \\
\text { (100-120 IU/kg/week) }\end{array}$ & $2.5-3.0$ & $13.3^{\mathrm{b}}$ \\
\hline BAX 855 & 2018 & 20 & $\begin{array}{l}\text { 40-50 IU/kg twice weekly [30] } \\
(80-100 \mathrm{IU} / \mathrm{kg} / \text { week })\end{array}$ & $7.6-9.5$ & NA \\
\hline
\end{tabular}

FVIII factor VIII, N8-GP turoctocog alfa pegol, $N A$ not available, $P E G$ polyethylene glycol, $Q 4 D$ every 4 th day

${ }^{\mathrm{a}} 179$ patient plasma samples analysed; borderline positive results during the extension were observed in five patients (maximum level: $119 \mathrm{ng} / \mathrm{mL}$ ) [23, 24]

${ }^{\mathrm{b}}$ Calculated combined mean PEG exposure from children, adolescents and adults from this study 
well aligned with values predicted based on rat distribution data. This suggests that modelling based on rat data can be used to predict plasma and tissue concentrations in humans.

Acknowledgements Bioanalysis of all plasma samples was performed by pharm-analyt Labor GmbH (Baden, Austria). Medical writing support was provided by Physicians World Europe GmbH, Mannheim, Germany, and supported by Novo Nordisk A/S.

\section{Compliance with Ethical Standards}

Funding This study was funded by Novo Nordisk A/S.

Conflict of interest Inga Bjørnsdottir, Birgitte Støvring, Tue Søeborg, Helene Jacobsen and Ola Sternebring are all current or former employees of Novo Nordisk A/S and are Novo Nordisk A/S shareholders.

Ethical approval All procedures performed in studies involving human participants were in accordance with the ethical standards of the institutional and/or national research committee and with the 1964 Helsinki declaration and its later amendments or comparable ethical standards.

Informed consent Informed consent was obtained from all individual participants included in the study or their legally appointed representatives.

Open Access This article is licensed under a Creative Commons Attribution-NonCommercial 4.0 International License, which permits any non-commercial use, sharing, adaptation, distribution and reproduction in any medium or format, as long as you give appropriate credit to the original author(s) and the source, provide a link to the Creative Commons licence, and indicate if changes were made. The images or other third party material in this article are included in the article's Creative Commons licence, unless indicated otherwise in a credit line to the material. If material is not included in the article's Creative Commons licence and your intended use is not permitted by statutory regulation or exceeds the permitted use, you will need to obtain permission directly from the copyright holder.To view a copy of this licence, visit http://creativecommons.org/licenses/by-nc/4.0/.

\section{References}

1. Srivastava A, Brewer AK, Mauser-Bunschoten EP, Key NS, Kitchen S, Llinas A, et al. Guidelines for the management of hemophilia. Haemophilia. 2013;19(1):e1-47. https://doi.org/10. 1111/j.1365-2516.2012.02909.x.

2. Veronese FM, Pasut G. PEGylation, successful approach to drug delivery. Drug Discov Today. 2005;10(21):1451-8. https://doi. org/10.1016/s1359-6446(05)03575-0.

3. Stennicke HR, Kjalke M, Karpf DM, Balling KW, Johansen PB, Elm T, et al. A novel B-domain $O$-glycoPEGylated FVIII (N8-GP) demonstrates full efficacy and prolonged effect in hemophilic mice models. Blood. 2013;121(11):2108-16. https ://doi.org/10.1182/blood-2012-01-407494.

4. Giangrande P, Andreeva T, Chowdary P, Ehrenforth S, Hanabusa H, Leebeek FW, et al. Clinical evaluation of glycoPEGylated recombinant FVIII: efficacy and safety in severe haemophilia A. Thromb Haemost. 2017;117(2):252-61. https://doi. org/10.1160/th16-06-0444.

5. Meunier S, Alamelu J, Ehrenforth S, Hanabusa H, Abdul Karim F, Kavakli K, et al. Safety and efficacy of a glycoPEGylated
rFVIII (turoctocog alpha pegol, N8-GP) in paediatric patients with severe haemophilia A. Thromb Haemost. 2017;117(9):1705-13. https://doi.org/10.1160/th17-03-0166.

6. Tiede A, Brand B, Fischer R, Kavakli K, Lentz SR, Matsushita $\mathrm{T}$, et al. Enhancing the pharmacokinetic properties of recombinant factor VIII: First-in-human trial of glycoPEGylated recombinant factor VIII in patients with hemophilia A. J Thromb Haemost. 2013;11(4):670-8. https://doi.org/10.1111/jth.12161.

7. Baumann A, Tuerck D, Prabhu S, Dickmann L, Sims J. Pharmacokinetics, metabolism and distribution of PEGs and PEGylated proteins: Quo vadis? Drug Discov Today. 2014;19(10):1623-31. https://doi.org/10.1016/j.drudis.2014.06.002.

8. Ivens IA, Achanzar W, Baumann A, Brandli-Baiocco A, Cavagnaro J, Dempster M, et al. PEGylated biopharmaceuticals: Current experience and considerations for nonclinical development. Toxicol Pathol. 2015;43(7):959-83. https://doi. org/10.1177/0192623315591171.

9. Turecek PL, Bossard MJ, Schoetens F, Ivens IA. PEGylation of biopharmaceuticals: a review of chemistry and nonclinical safety information of approved drugs. J Pharm Sci. 2016;105(2):46075. https://doi.org/10.1016/j.xphs.2015.11.015.

10. Fletcher AM, Tellier P, Douville J, Mansell P, Graziano MJ, Mangipudy RS, et al. Adverse vacuolation in multiple tissues in cynomolgus monkeys following repeat-dose administration of a PEGylated protein. Toxicol Lett. 2019;317:120-9. https:// doi.org/10.1016/j.toxlet.2019.09.023.

11. EMA. Jivi ${ }^{\circledR}:$ EPAR - product information; 2019. https://www. ema.europa.eu/en/documents/product-information/jivi-eparproduct-information_en.pdf. Accessed 18 Sept 2019.

12. FDA. Cimzia: pharmacology reviews. BLA 125160/0; 2008. https://www.accessdata.fda.gov/drugsatfda_docs/ nda/2008/125160s000_PharmR_P1.pdf. Accessed 12 Aug 2019.

13. FDA. Omontys: Pharmacology reviews. Application number: 202799Orig1s000; 2012. https://www.accessdata.fda.gov/drugs atfda_docs/nda/2012/202799Orig1s000PharmR.pdf. Accessed 12 Aug 2019.

14. Bjornsdottir I, Sternebring O, Kappers WA, Selvig H, Korno HT, Kristensen JB, et al. Pharmacokinetics, tissue distribution and excretion of 40kDa PEG and PEGylated rFVIII (N8-GP) in rats. Eur J Pharm Sci. 2016;87:58-68. https://doi.org/10.1016/j. ejps.2015.10.020.

15. Ito S. Pharmacokinetics 101. Paediatr Child Health. 2011;16(9):535-6. https://doi.org/10.1093/pch/16.9.535.

16. Rowland M, Tozer TN. Clinical pharmacokinetics: concepts and applications. 4th ed. Baltimore: Williams and Wilkins; 2011.

17. Rasmussen CE, Nowak J, Larsen JM, Moore E, Bell D, Liu $\mathrm{KC}$, et al. Long-term safety of PEGylated coagulation factor VIII in the immune-deficient Rowett nude rat. J Toxicol. 2017;2017:8496246. https://doi.org/10.1155/2017/8496246.

18. Curry N, Albayrak C, Escobar M, Andre Holme P, Kearney $\mathrm{S}$, Klamroth R, et al. Once-weekly prophylaxis with glycoPEGylated recombinant factor VIII (N8-GP) in severe haemophilia A: safety and efficacy results from pathfinder 2 (randomized phase III trial). Haemophilia. 2019;25(3):373-81. https://doi. org/10.1111/hae.13712.

19. Sternebring O, Gabel-Jensen C, Jacobsen H, Benie AJ, Bjornsdottir I. Steady-state plasma concentrations of polyethylene glycol (PEG) are reached in children and adults during once-weekly prophylactic treatment with nonacog beta pegol (N9-GP). BioDrugs. 2019;33(6):673-81. https://doi.org/10.1007/s40259-019-00380-3.

20. Carcao M, Zak M, Abdul Karim F, Hanabusa H, Kearney S, Lu MY, et al. Nonacog beta pegol in previously treated children with hemophilia B: results from an international open-label phase 3 trial. J Thromb Haemost. 2016;14(8):1521-9. https://doi. org/10.1111/jth.13360. 
21. Collins PW, Young G, Knobe K, Karim FA, Angchaisuksiri P, Banner C, et al. Recombinant long-acting glycoPEGylated factor IX in hemophilia B: a multinational randomized phase 3 trial. Blood. 2014;124(26):3880-6. https://doi.org/10.1182/blood -2014-05-573055.

22. Timperio AM, Gevi F, Grazzini G, Vaglio S, Zolla L. Comparison among plasma-derived clotting factor VIII by using monodimensional gel electrophoresis and mass spectrometry. Blood Transfus. 2010;8(Suppl 3):s98-104. https://doi.org/10.2450/2010.016s.

23. Baumann A, Piel I, Hucke F, Sandmann S, Hetzel T, Schwarz T. Pharmacokinetics, excretion, distribution, and metabolism of 60-kDa polyethylene glycol used in BAY 94-9027 in rats and its value for human prediction. Eur J Pharm Sci. 2019;130:11-20. https://doi.org/10.1016/j.ejps.2019.01.015.

24. Maas Enriquez M, Katterle Y, Baumann A, Michaels LA, Saxena K. BAY 94-9027 PROTECT VIII studies: observation of pharmacokinetic steady state for $60-\mathrm{kDa}$ PEG demonstrates the existence of elimination processes for PEG. Abstract presented at the World Federation of Hemophilia World Congress 2018, May 20-24, Glasgow, Scotland. Haemophilia. 2018;24 Suppl 5:3-196. https://doi.org/10.1111/hae.13478.

25. Yamaoka T, Tabata Y, Ikada Y. Distribution and tissue uptake of poly(ethylene glycol) with different molecular weights after intravenous administration to mice. J Pharm Sci. 1994;83(4):601-6. https://doi.org/10.1002/jps.2600830432.
26. EMA. CHMP Safety Working Party's response to the PDCO regarding the use of PEGylated drug products in the paediatric population; 2012. https://www.ema.europa.eu/en/documents/scien tific-guideline/chmp-safety-working-partys-response-pdco-regar ding-use-pegylated-drug-products-paediatric-population_en.pdf. Accessed 23 Aug 2019.

27. FDA. Guidance for industry: Estimating the maximum safe starting dose in initial clinical trials for therapeutics in adult healthy volunteers; 2005. https://www.fda.gov/media/72309/download. Accessed 25 Oct 2019

28. Stidl R, Denne M, Goldstine J, Kadish B, Korakas KI, Turecek PL. Polyethylene glycol exposure with antihemophilic factor (recombinant), PEGylated (rurioctocog alfa pegol) and other therapies indicated for the pediatric population: history and safety. Pharmaceuticals (Basel). 2018;11(3). https://doi.org/10.3390/ph110 30075.

29. EMA. Esperoct ${ }^{\circledR}:$ EPAR - Product information; 2019. https:// www.ema.europa.eu/en/documents/product-information/esper oct-epar-product-information_en.pdf. Accessed 18 Sep 2019.

30. EMA. Adynovi ${ }^{\circledR}$ : EPAR - Product information; 2019. https:// www.ema.europa.eu/en/documents/product-information/adyno vi-epar-product-information_en.pdf. Accessed 18 Sep 2019. 